\title{
LA CONSOLIDACIÓN DEL PROCESO DE GENERACIÓN DE DESIGUALDAD SOCIAL EN LOS SISTEMAS URBANOS CONTEMPORÁNEOS. LA CIUDAD NEGOCIO.
}

\author{
Alejandro Tamayo Palacios (Dr. Arquitecto - Profesor asociado DUyOT)
}

La observación del espacio social de las periferias construidas durante las últimas décadas en las ciudades occidentales muestra importantes diferencias entre éstos ámbitos y la ciudad tradicional en cuanto a la segregación social del territorio. Frente a unos tejidos donde convivían, incluso en los mismos edificios, población de muy diferente condición, las periferias actuales muestran una gran diferenciación entre las clases de barrios. Esta constatación nos indica que el desarrollo de los sistemas urbanos postfordistas contiene un proceso de segregación social del territorio de una dimensión sin precedentes. La cuestión no es nueva, desde el siglo XIX es comúnmente aceptado que las transformaciones urbanas han ido de la mano, generalmente, de una reordenación espacial de la población, pero la escala de este proceso en las últimas décadas si es algo destacable. Para abordar esta cuestión se plantea en este artículo que el fenómeno descrito tiene que ver con la natural deriva de las ciudades de un sistema capitalista que se desarrolla sobre el territorio a través de un modelo inmobiliario que, para poder funcionar, necesita reproducir la estructura social existente mediante una oferta muy jerarquizada y ordenada que debe ser percibida en estos términos.

\section{EL MODELO INMOBILIARIO Y LA REPRODUCCIÓN SOCIAL}

En cuanto a la natural deriva de los sistemas urbanos contemporáneos hacia la clasificación y ordenación de la población en el territorio habría que señalar dos aspectos muy importantes que se encuentran estrechamente vinculados: el modelo inmobiliario y la estructura social. No se pretende plantear en este artículo que quien determina el proceso descrito sea el modelo inmobiliario, sino que la materialización a través de éste, condicionada por sus mecanismos de funcionamiento, consolida físicamente un fenómeno que tiene sus raíces en la reproducción de la estructura social. Se trataría de un fenómeno de materialización espacial de la estructura de clases que conforma la población. Dentro de este proceso de reproducción social la necesidad actual de que la población se sitúe sobre el territorio de forma clara y ordenada tiene mucho que ver con los mecanismos de funcionamiento de un sistema capitalista sustentado en el sector financiero. En este sentido, la única forma de garantizar a medio plazo las inversiones inmobiliarias encargadas de materializar el desarrollo de las ciudades, es a través de una ordenación espacial de las promociones muy precisa. Así, el desarrollo inmobiliario "culpable" de la forma en que han crecido los sistemas urbanos contemporáneos se encuentra condicionado por un sector financiero que obliga a la clasificación del territorio ${ }^{95}$. Por otro lado la reproducción de la estructura social en un dibujo que incorpore todos los niveles de las jerarquías

\footnotetext{
95 Respecto a la vinculación entre el modelo inmobiliario y el sector financiero es importante señalar como la legislación española incorporó entre 1956 y 1966 leyes que permitieron financiar operaciones inmobiliarias y facilitaron la venta de pisos individuales en edificios aún sin construir y regularon la inscripción de estos procesos.
} 
existentes tiene que ver con otro requisito de los desarrollos inmobiliarios. En un contexto de promoción residencial basado en la venta financiada de viviendas sólo es posible asegurar el negocio inmobiliario si existe una clara correspondencia entre la capacidad de endeudamiento de la población, traducidos en un entorno de cierta estabilidad en sus niveles de renta, y los precios de la vivienda. No obstante, habría que volver a incidir en que sólo se entiende el papel desempeñado por los sectores financiero e inmobiliario y la dimensión del fenómeno considerando la evolución de la estructura social durante el periodo señalado, ya que éstos simplemente son los encargados de reproducir esa estructura.

En este sentido hay que destacar un aspecto que diferencia a la sociedad postfordista de su predecesora: el surgimiento de una proporción importante de población asalariada con capacidad de endeudamiento. Una vez que se ha planteado el papel del modelo inmobiliario como un mero constructor de un dibujo preestablecido por dinámicas de largo recorrido, habría que señalar cómo éste, a su vez, también interviene en la necesidad de que la reproducción social se materialice sobre el territorio de una forma clara y ordenada. El modelo inmobiliario no determina a su antojo el mosaico apreciado en el territorio, lógicamente no puede alterar por sí mismo la estructura de clases existentes, pero la forma en que "construye" ese mosaico si tiene que ver con sus mecanismos de funcionamiento. Podríamos decir que se trata de un fenómeno doble de producción inmobiliaria y reproducción social donde el modelo inmobiliario está determinado pero a su vez acaba siendo determinante. En cuanto a los mecanismos del modelo inmobiliario éstos no dejan de ser instrumentos que le permiten funcionar de forma eficiente. ¿Qué hace falta para alcanzar esa eficiencia? Fundamentalmente dos cuestiones: reproducir con fidelidad la jerarquía social y ordenarla en el territorio. Por un lado la reproducción de la jerarquía social es necesaria para establecer el puente entre las capacidades de la población dispuesta a adquirir una vivienda y la oferta residencial y, por otro, el orden garantiza que la inversión financiera se mantenga. La necesidad de garantizar la inversión financiera lleva a clasificar los precios sobre el territorio de forma que haya el mínimo error en su percepción. El modelo inmobiliario se dotó para ello de una regulación que introducía la valoración a través de las áreas de valor ${ }^{96}$. Así obtenemos, que el modelo inmobiliario actuaba de la mano del sistema financiero y requería construir un parque residencial de una diversidad jerarquizada muy ordenada sobre el territorio.

Si contemplamos que el modelo operaba principalmente bajo un régimen de venta de viviendas y consideramos que sus compradores podían acceder a un sistema financiero que convertiría toda su capacidad de endeudamiento futuro en una localización que se correspondiera con el máximo estatus al que podían acceder podemos llegar a la conclusión de que el resultado iba a ser un espacio de acumulación y exclusión sin precedentes. La vinculación total entre pertenencia a un determinado rango de capacidad económica y dirección postal se convirtieron en una seña de identidad de los sistemas urbanos actuales. Respecto al papel del sector inmobiliario como transmisor de este proceso es muy interesante observar como hay una relación absoluta entre el precio de las viviendas en relación a la media anual y el espacio

\footnotetext{
96 En España se establecieron las áreas de valor mediante el Reglamento Hipotecario de 1960.
} 
social resultante décadas después ${ }^{97}$. A partir de esta constatación se puede llegar a considerar que durante el doble fenómeno de transformación inmobiliaria y social que vivieron los sistemas urbanos en el siglo XX se produjo un cambio de fase en el modelo de configuración de la ciudad. Estaríamos ante la transformación del modelo de ciudad fordista en un nuevo modelo que hemos denominado "Ciudad Negocio". En este nuevo modelo el sector inmobiliario, olvidándose del antiguo sistema basado en el alquiler, conseguiría producir viviendas para vender a largo plazo a un ritmo desconocido hasta la fecha mediante mecanismos que facilitaban promocionar y vender viviendas sin ni siquiera haber puesto un ladrillo. ${ }^{98}$

\section{EL MODELO DE CIUDAD NEGOCIO}

En el nuevo modelo de ciudad, la concepción, construcción, venta y financiación de su propio crecimiento son el negocio central. No se trata de que la ciudad facilite el negocio inmobiliario, su razón de ser, el motivo por el que se configura de una forma y no de otra, es el negocio en sí. Podríamos afirmar, que la ciudad se convierte en una suerte de gran y diversificada operación financiera. Como ya se ha visto la búsqueda de beneficios del sector inmobiliario y los mecanismos de funcionamiento del sector financiero obligan a que el mapa de precios de las viviendas coincida en todos los aspectos con el mapa de rentas que refleja el espacio social de la ciudad. La utilización del precio de la vivienda, y con ella de la capacidad de endeudamiento de la población, como filtro de exclusión social llevaría, más adelante, a que los costes se acercaran al límite de capacidad de cada estrato social, es decir, al ahorro de toda su vida laboral. El espacio social se acabaría convirtiendo en un espacio de acumulación y exclusión (sistémica) excesivamente dependiente del sistema financiero. El nuevo modelo de ciudad confirma la vocación del sistema capitalista por producir y reproducir desigualad y la obligación de que esa desigualdad se perciba con claridad por la población. Por otro lado el aumento de la capacidad de endeudamiento, la imagen de riqueza que trasmitía una propiedad en constante revalorización, el alargamiento de los plazos, la incorporación masiva de suelo al que se le añadían grandes expectativas y las grandes infraestructuras realizadas por la administración, acabaron de impulsar un crecimiento acelerado de los sectores financiero e inmobiliario que generó una peligrosa asociación entre el desarrollo inmobiliario y el crecimiento de la economía y el empleo. Llegados a este punto, habría que señalar que las condiciones de entorno en las que se produjo la transformación del modelo urbano descrito fueron, entre otras, la escasez de viviendas, un aumento constante de la población asalariada, el desmantelamiento del modelo de alquiler, ayudas públicas a la compra de vivienda, un contexto económico internacional de bonanza económica, facilidades de financiación, energía relativamente barata y patrones de consumo en aumento. El escenario actual de freno en seco de la financiación, acumulación de viviendas vacías, y disminución de la masa de población asalariada pone sobre la mesa importantes incógnitas sobre la evolución actual del modelo descrito.

\footnotetext{
97 Esta cuestión se puede comprobar en los datos recogidos por la Tesis doctoral del autor de este artículo Tamayo, A. (2015) Desigualdad social en la Ciudad Negocio. El modelo inmobiliario en la construcción social de Madrid durante el desarrollismo (inédita)

98 En el caso de España la Ley de Propiedad Horizontal, la Ley Hipotecaria y el Reglamento Hipotecario, entre otras, fueron las culpables de la transformación de un modelo basado en el alquiler a otro condicionado totalmente por la venta y financiación de viviendas.
} 